\title{
Platelet-activating Factor Mediates Hemodynamic Changes and Lung Injury in Endotoxin-treated Rats
}

Shih-Wen Chang, Christian O. Feddersen, Peter M. Henson, and Norbert F. Voelkel

Cardiovascular Pulmonary Research Laboratory, University of Colorado Health Sciences Center, Denver, Colorado 80262; and National Jewish Center for Immunology and Respiratory Medicine, Denver, Colorado 80206

\begin{abstract}
Within 20 min after intraperitoneal injection of Salmonella enteritidis endotoxin in rats, blood platelet-activating factor (PAF) increased from $4.3 \pm 1.3$ to $13.7 \pm 2.0 \mathrm{ng} / \mathrm{ml}(P<0.01)$ and lung PAF from $32.3 \pm 4.9$ to $312.3 \pm 19.6 \mathrm{ng}(P<0.01)$, but not lung lavage PAF. We tested the effect of PAF receptor antagonists, CV 3988 and SRI 63-441, on endotoxin-induced hemodynamic changes and lung vascular injury. Pretreatment with CV 3988 attenuated systemic hypotension, preserved hypoxic pulmonary vasoconstriction, and prolonged survival of awake catheter-implanted endotoxin-treated $(20 \mathrm{mg} / \mathrm{kg})$ rats. Pretreatment with SRI 63-441 prevented the depressed hypoxic pulmonary vasoconstriction after low dose ( $2 \mathrm{mg} / \mathrm{kg}$ ) endotoxin. Both CV 3988 and SRI 63-441 blocked the increased extravascular accumulation of ${ }^{125} \mathrm{I}$-albumin and water in perfused lungs isolated from endotoxin-treated rats. We conclude that PAF is produced in the lung during endotoxemia and may be an important mediator of the systemic and pulmonary hemodynamic changes as well as the acute lung vascular injury after endotoxemia.
\end{abstract}

\section{Introduction}

Administration of endotoxin to experimental animals is associated with major alterations in systemic and pulmonary hemodynamics, leukopenia, metabolic acidosis, and acute lung injury characterized by increased pulmonary vascular permeability (1). Synthesis and release of various pro-inflammatory substances occur after endotoxemia. These inflammatory mediators include histamine, kinins, serotonin, activated complement fragments, and various metabolites of arachidonic acid (1-4). Although chemotaxis and either constriction or dilation of various vascular segments have been described for many of these mediators, it is still unclear whether mediator actions can explain all of the hemodynamic, metabolic, and pulmonary vascular permeability changes after endotoxemia (5-7). Part of the failure to relate endotoxin-induced alterations to specific mediator actions may have been attributable to the fact that either an important mediator had not yet been considered or not one single mediator but rather synergistic action and/or a cascade of several mediators was (were) involved (8).

Portions of this work were presented at the Symposium on New Frontiers in Platelet-activating Factor Research, 16-18 October 1985, Hilton Head Island, SC, and at the annual meeting of the American Thoracic Society, May 1986. 1987.

Received for publication 9 June 1986 and in revised form 13 January

J. Clin. Invest.

(C) The American Society for Clinical Investigation, Inc.

0021-9738/87/05/1498/12 \$1.00

Volume 79, May 1987, 1498-1509
Recently, platelet-activating factor (PAF, ${ }^{1}$ 1-O-alkyl-2-acetyl$s n$-glycerophosphorylcholine), a potent ether lipid, has been suggested as an important mediator in endotoxic shock (9-11). This suggestion is based on the following evidence: $(a)$ infusion of exogenous PAF into whole animals caused systemic hypotension, decreased cardiac output $(12,13)$, and increased pulmonary vascular permeability (14-16); (b) PAF is produced during experimental gram-negative sepsis and endotoxic shock $(10,11) ;(c)$ two structurally different PAF antagonists, CV 3988 and kadsurenone, have been reported to inhibit endotoxin-induced hypotension and prolong survival in rats $(9,10)$.

In the previous studies using PAF antagonists $(9,10)$, only the effect on endotoxin-induced systemic hypotension was examined. Because endotoxin causes complex alterations in pulmonary hemodynamics and often leads to acute lung injury, we wondered whether PAF also mediates the pulmonary hemodynamic changes and the change in lung vascular permeability after endotoxin.

Our approach was first to document an increase in PAF concentrations of blood and lung after intraperitoneal injection of endotoxin in rats. We then tested the effect of specific PAF receptor antagonists, CV 3988 and SRI 63-441, on endotoxininduced changes in systemic and pulmonary hemodynamics in awake, catheterized rats. In addition, we developed an in vitro method for measuring lung injury subsequent to endotoxin administration and assessed the effects of three different PAF receptor antagonists, CV 3988, SRI 63-441, and RP 48740, on the increased pulmonary vascular permeability after endotoxin. Because neutrophils are sequestered in the lung after endotoxemia and could contribute to PAF release or could be stimulated by PAF released from other cells to cause lung injury, we studied the effect of neutropenia on both the lung PAF level and the increased pulmonary vascular permeability after endotoxin.

\section{Methods}

\section{Measurement of PAF}

Blood and tissue collection. Male Sprague-Dawley rats (270-310 g) were obtained from a commercial vendor (Sasco, Omaha, NE) and allowed free access to food and water. Endotoxin-treated animals received 20 $\mathrm{mg} / \mathrm{kg}$ i.p. of Salmonella enteritidis lipopolysaccharide B (Batch No. 728539, Difco Laboratories, Detroit, MI) at time 0, and their blood or tissues were collected at the time points indicated below. Control animals were litter mates and received no treatment before blood or tissue collection. At the time of sampling, the rats were anesthetized with pentobarbital $(100 \mathrm{mg} / \mathrm{kg}$ i.p.), and their chest opened via a median sternotomy. $4 \mathrm{ml}$ of blood was withdrawn from the right ventricle under direct vision and placed immediately into a ice-chilled test tube containing $0.45 \mathrm{ml}$ of citric acid to inhibit the action of plasma acetylhydrolase (17). The sample was centrifuged at $550 \mathrm{~g}(1,600 \mathrm{rpm})$ for $2 \mathrm{~min}$ and 1

1. Abbreviation used in this paper: PAF, platelet-activating factor. 
$\mathrm{ml}$ of the plasma removed into $18 \mathrm{ml}$ of chloroform/methanol/water (1: 2:0.8 [vol/vol]).

The pulmonary artery was cannulated through an incision in the right ventricle. Residual blood in the lung was removed by slowly infusing $10 \mathrm{ml}$ of normal saline into the pulmonary artery, allowing the fluid to drain through an incision in the left ventricle. The lungs were then removed, placed in $25 \mathrm{ml}$ of ice-cold methanol, and homogenized in a model SDt 1810 Tissumizer (Tekmar Co., Cincinnati, OH). Both kidneys were removed, placed into $25 \mathrm{ml}$ of chilled methanol, and homogenized. Blood and lungs were collected at 5, 20, 60, 90, and 120 min after endotoxin injection, and kidneys were collected at 10,20,60,90,120, and 180 min after endotoxin. A total of 20 blood, 28 lung, and 23 kidney samples were obtained in endotoxin-treated animals. Four blood, five lung, and four kidney samples were obtained from control animals.

Because pulmonary lavage may reflect the inflammatory state of the lung parenchyma in some clinical situations (18), we also measured PAF in lung lavage fluid in a separate group of rats. In the first experiment, four control and four endotoxin-treated animals ( $90 \mathrm{~min}$ after endotoxin $20 \mathrm{mg} / \mathrm{kg}$ i.p.) received whole-lung lavage with normal saline via a tracheal cannula. $5 \mathrm{ml}$ of saline was alternatively instilled into and aspirated from the trachea, and the recovered lavage fluid placed into a tube containing $30 \mathrm{ml}$ of ice-chilled methanol. This was repeated four times, recovering an average of $17 \mathrm{ml}$ of fluid out of the initial $20 \mathrm{ml}$. To see whether addition of albumin to the lavage fluid would enhance the recovery of PAF from the lung (19), an additional five control and five endotoxic rats (90 min after endotoxin) were lavaged in a similar manner using 20 $\mathrm{ml}$ of normal saline containing $0.25 \%$ bovine serum albumin (Sigma Chemical Co., St. Louis, MO). Finally, to obtain a positive control for PAF in the lavage fluid, the lungs from a control rat were isolated and perfused with physiologic salt solution (as described below) and challenged with the addition of $10^{-4} \mathrm{M}$ calcium ionophore A23187 (CalbiochemBehring Corp., San Diego, CA) to the perfusate. 3 min later, the lungs were lavaged with $20 \mathrm{ml}$ of normal saline and the lavage fluid was analyzed for PAF.

Effect of neutropenia. In a separate group of 20 rats the effect of neutropenia on the lung PAF levels after endotoxin was studied. In 10 rats neutropenia was induced by injection of $0.75 \mathrm{mg} / \mathrm{kg}$ vinblastine sulfate (Sigma Chemical Co.) into the tail vein (20). In a preliminary study, we determined that this dose of vinblastine caused severe neutropenia that was maximal on days 4 and 5 . Therefore, subsequent studies were performed on day 4 or 5 after vinblastine injection. 5 of the 10 neutropenic rats received endotoxin $20 \mathrm{mg} / \mathrm{kg}$ i.p. and their lungs were collected $90 \mathrm{~min}$ later. The PAF levels were also measured in lungs from five neutropenic and five nonneutropenic rats receiving saline injection and five nonneutropenic rats receiving endotoxin.

Tissue processing. Plasma, lung and kidney homogenates, and lung lavage were processed in a similar manner. Each tissue sample underwent a Bligh-Dyer total lipid extraction (21), and was then further purified by passing through a silicic acid column. After the last step of the BlighDyer extraction, the sample was loaded onto the silicic acid column in a 95:5 chloroform/methanol mixture. The column was then sequentially washed with various mixture of solvents. The effluents from washes with 95:5 and 80:20 chloroform/methanol mixtures and 100\% methanol were discarded. The effluents from subsequent washes with 70:30 methanol/ water were collected and subjected to a second Bligh-Dyer lipid extraction. The final sample was resuspended in Krebs-Ringer phosphate dextrose buffer with $0.25 \%$ nonpyrogenic human serum albumin (Miles Scientific, Naperville, IL), an aliquot of which was used for the PAF assay.

$P A F$ assay. Bioassay for PAF was performed by measuring the release of $\left[{ }^{3} \mathrm{H}\right]$ serotonin from rabbit platelets as described previously (22). Briefly, blood was collected from the central ear artery of New Zealand white rabbits $(2.5-4 \mathrm{~kg})$ into a $1.7 \mathrm{vol}$ of acid citrate dextrose and centrifuged at $300 \mathrm{~g}$ for 20 minutes. A pool of the resultant platelet-rich plasma was then incubated for 30 min with $1 \mu \mathrm{Ci}$ of $\left[{ }^{3} \mathrm{H}\right]$ serotonin binoxalate (New England Nuclear, Boston, MA) at $37^{\circ} \mathrm{C}$. The platelets were sedimented at $2,500 \mathrm{~g}$ for $15 \mathrm{~min}$ and washed in Tyrode's gelatin without calcium in the presence of $0.1 \mathrm{mM}$ EGTA. The platelets were again pelleted and washed in Tyrode's gelatin without calcium (no EGTA). After a final centrifugation, the platelets were resuspended in Tyrode's gelatin without calcium to a concentration of $1.25 \times 10^{9}$ (determined by absorbance at $530 \mathrm{~nm}$ ). Each reaction tube contained various dilutions of the sample to be assayed in a 450- $\mu$ l vol of Tyrode's gelatin with calcium to which $50 \mu \mathrm{l}$ of the platelet preparation was added. After $90 \mathrm{~s}$ of incubation at room temperature, the reaction was stopped by the addition of $20 \mu \mathrm{l}$ of $9 \%$ formaldehyde. After centrifugation at $2,500 \mathrm{~g}$ for $15 \mathrm{~min}, 100 \mu \mathrm{l}$ of the supernatant was removed into $3 \mathrm{ml}$ of scintillant (Scintiverse II, Fisher Scientific Co., Pittsburgh, PA). The samples were counted for radioactivity in a liquid scintillation counter (model 8000 , Beckman Instruments, Inc., Fullerton, CA). The reported counts per minute were converted to disintegrations per minute using the $\mathrm{H}$ number and a quench curve generated specifically for the scintillant, vials, and buffer employed in this assay. The platelets in one reaction tube containing only buffer and platelets were lysed by Triton X-100 and counted to determine the maximal radioactivity in this batch of platelets. The bioactivity in each sample was expressed as a percentage of the total radioactivity released and reported in nanogram equivalents of PAF after comparison with a standard curve of serotonin-release elicited by known amounts of synthetic hexadecyl PAF (Bachem Chemicals, Bubendorf, Switzerland). In 10 samples, addition of known amounts of synthetic PAF before the purification process resulted in recovery rates ranging from $85 \%$ to $95 \%$. Thus, values for PAF are here reported without correction for recovery.

\section{Hemodynamic studies}

Animal preparation. Male Sprague-Dawley rats (290-350 g) were anesthetized with $50-100 \mathrm{mg} / \mathrm{kg}$ of ketamine hydrochloride and $5 \mathrm{mg} / \mathrm{kg}$ of xylazine intramuscularly. Using sterile instruments, the right carotid artery was cannulated with a PE-50 catheter (internal diameter $0.58 \mathrm{~mm}$ ) and ligated distally. A polyvinyl catheter (PV 1, internal diameter 0.28 $\mathrm{mm}$ ) with a shallow bend at its tip was inserted into the right jugular vein and guided into the main pulmonary artery. The location of the catheter was verified by the characteristic pulmonary artery pressure tracing displayed on an oscilloscope. After the pulmonary artery catheter was in place, a second catheter (PV 1) with a straight tip was introduced into the same vein and advanced into the superior vena cava. Finally, a fourth catheter (PE 50) was placed in the left jugular vein. All catheters used were previously sterilized with sporicidin (diluted 1:16 in water), and flushed with heparinized saline. After placement, the catheters were tied to prevent backflow and tunneled subcutaneously to the back of the neck. The catheters were protected in a plastic housing sutured to the skin and covered with a rubber cap. Over $90 \%$ of catheters prepared in this way remained patent for up to $72 \mathrm{~h}$.

Hemodynamic measurements. After recovery from anesthesia (24$48 \mathrm{~h}$ later), the awake rats were studied in a small rectangular plastic chamber. Only rats that appeared grossly healthy with body weight changes $<10 \%$ of the presurgery values were used. An inlet on the wall of the chamber allowed ventilation of the chamber with either normoxic (room air, Denver altitude $1,600 \mathrm{~m}$ ) or hypoxic $\left(8 \% \mathrm{O}_{2}\right)$ gas. The catheters were irrigated with heparinized saline and connected to $\mathrm{P} 23 \mathrm{Db}$ transducers (Statham, Oxnard, CA) for measurement of heart rate and aortic pressure (via the carotid catheter) and mean pulmonary artery pressure (via pulmonary artery catheter). The other two venous catheters provided access for fluid, drug, or dye injection. The pressure tracings were displayed on an oscilloscope and the mean pressures and heart rate were calculated by a Nova computer (Data-General, Southboro, MA). Cardiac outputs were measured using the dye-dilution method described previously (23-25). Systemic vascular resistance and total pulmonary resistance were calculated by dividing mean aortic pressure and mean pulmonary artery pressure by the cardiac output. Hypoxic challenges were performed by overflowing the study chamber with $8 \% \mathrm{O}_{2}$ for $5 \mathrm{~min}$. The hypoxic pressor response was expressed as the difference between the maximal mean pulmonary artery pressure during hypoxia and the mean pulmonary artery pressure immediately preceding hypoxia. Blood samples $(0.5 \mathrm{ml}$ each) were drawn from the aortic catheter for measurements of blood gas tensions and pH (Corning microelectrodes, Corning Glass, Medford, 
MA), and for measurements of hematocrit and white blood cell count The alveolar-arterial gradient for oxygen was calculated using the formula: $122-\left(\mathrm{PCO}_{2} / 0.8\right)-\mathrm{PO}_{2}$. This assumes that the blood gas was obtained while the animal breathed room air with the Denver barometric pressure averaging 635 torr.

Effect of CV 3988 on PAF-induced hemodynamic changes. CV 3988, RS-2-methoxy-3-(octadecylcarbamoyl-oxy)propyl-2-(3-thiazolio)ethyl phosphate, a specific PAF receptor antagonist (26), was a kind gift of Dr. Walter Pickett (Lederle Laboratory, American Cyanamid Co., N.J.). Synthetic PAF was purchased from Sigma Chemical Co. and stored in chloroform. Before use, the chloroform was evaporated and the PAF was diluted in normal saline containing $0.25 \%$ bovine serum albumin. In four awake, hemodynamically monitored rats, PAF was administered as an intravenous bolus injection of $10 \mathrm{ng} / 0.1 \mathrm{ml}$ during an ongoing hypoxic challenge when the mean pulmonary artery pressure was elevated and had reached a plateau. Mean aortic and pulmonary artery pressures were monitored every $30 \mathrm{~s}$ for $3 \mathrm{~min}$ after PAF injection. The hypoxic challenge was then stopped and after 15 min of normoxic condition, $\mathrm{CV}$ $3988(10 \mathrm{mg} / \mathrm{kg})$ was given as a slow intravenous infusion in $0.6 \mathrm{ml}$ of normal saline. 30, 60, and $90 \mathrm{~min}$ later (and in two rats, $120 \mathrm{~min}$ later) the animals were exposed to additional periods of hypoxia during which PAF was injected as described above. The effect of PAF on mean aortic and pulmonary artery pressures before and after CV 3988 were compared. In three additional rats that did not receive CV 3988, PAF was administered during five successive hypoxic challenges each $30 \mathrm{~min}$ apart to demonstrate that tachyphylaxis to PAF did not occur with this protocol.

Effect of CV 3988 on endotoxin-induced hemodynamic changes. Four groups of awake, catheter-implanted rats were studied: $(a)$ control animals $(n=5)$ served to demonstrate the normal progression of hypoxic pressor responses and the stability of hemodynamic measurements over the time course of the study; $(b)$ endotoxin animals $(n=7)$ received $20 \mathrm{mg} / \mathrm{kg}$ i.p. of $S$. enteritidis lipopolysaccharide at time 0; (c) endotoxin/CV 3988 animals $(n=6)$ received CV 3988 (in $30 \%$ ethanol) $10 \mathrm{mg} / \mathrm{kg}$ i.v. $5 \mathrm{~min}$ before and $5 \mathrm{mg} / \mathrm{kg}$ i.v. $50 \mathrm{~min}$ after endotoxin: $(d)$ endotoxin/ethanol animals $(n=6)$ received similar volumes of $30 \%$ ethanol i.v. at the corresponding time points of CV 3988 infusion. Endotoxin was reconstituted with normal saline (to $10 \mathrm{mg} / \mathrm{ml}$ ), stored at $4^{\circ} \mathrm{C}$, and used within 2 wk. CV 3988 was made up fresh on the day of the study.

At the beginning of the study the rats were weighed, and placed in the study chamber. Each rat received three hypoxic challenges with $8 \%$ $\mathrm{O}_{2}$ to establish the baseline hypoxic pressor responses. The hypoxic challenges were separated by 20 min of normoxia. Heart rate and mean aortic and pulmonary artery pressures were measured every minute during normoxia and every $20 \mathrm{~s}$ during hypoxia. Baseline cardiac outputs were obtained at two different time points during normoxia. $10 \mathrm{~min}$ before endotoxin was given, a baseline arterial blood sample was taken for measurements of gas tensions, $\mathrm{pH}$, white blood cell counts, and hematocrit. After endotoxin administration at time 0 , cardiac outputs and hypoxic pressor responses were assessed 30 and $60 \mathrm{~min}$ later. A second arterial blood sample was obtained 75-80 min after endotoxin. $90 \mathrm{~min}$ after the administration of endotoxin, the catheters were tied off and the study terminated. The overall length of the study was $\sim 3 \mathrm{~h}$. The rat was placed back in the cage and observed for the time of death to the nearest hour. Mean systemic and pulmonary artery pressures, cardiac outputs, systemic vascular and total pulmonary resistances, hypoxic pressor responses, and blood gas values after endotoxin were compared.

Because we observed some effect of ethanol on endotoxin-induced cardiac depression (see Results), in five additional catheterized rats, we studied the effects of CV 3988 dissolved in normal saline (without ethanol) and given as a continuous infusion. The protocol for pressure, cardiac output, hypoxic pressor response, arterial blood gas, and blood count measurements was as described above. In addition to the $10 \mathrm{mg} / \mathrm{kg}$ i.v. of CV 3988 given 5 min before endotoxin, CV 3988 was infused at $\mathbf{0 . 2}$ $\mathrm{mg} / \mathrm{kg}$ per min i.v. (Multi-speed Transmission Pump, Harvard Apparatus Co., Inc., S. Natick, MA) immediately after endotoxin injection. The infusion continued for $80 \mathrm{~min}$, with a total infused volume of $2.5 \mathrm{ml}$ or less. In this experiment, CV 3988 was dissolved initially in a small volume of $100 \%$ ethanol, evaporated to dryness with nitrogen, and then resuspended in warm saline. At the end of this infusion protocol, ethanol was undetectable in blood samples from these rats.

Effect of SRI 63-441 on hypoxic pulmonary vasoconstriction after low-dose endotoxin. 10 additional awake, catheter-implanted rats were studied. At the beginning of the study each rat was exposed to two hypoxic challenges to establish its baseline hypoxic pressor response. Baseline mean systemic and pulmonary artery pressures and cardiac output were also obtained. Five rats then received SRI $63-441(20 \mathrm{mg} / \mathrm{kg}$ i.v. in saline) over a 2-min period, while the other five rats (vehicle controls) received saline infusion. SRI 63-441, cis( \pm )-1-[2-hydroxy[tetrahydro-5-[(octadecylaminocarbonyl)oxy]methyl]furan-2-yl]methoxyphosphinyloxy]ethyl]quinolinium hydroxide, is a recently described PAF receptor antagonist (27) and a generous gift from Dr. Dean Handley (Sandoz Research Institute, East Hanover, NJ). 5 min after infusion of either SRI 63-441 or saline, all 10 rats received $2 \mathrm{mg} / \mathrm{kg}$ i.v. of $S$. enteritidis endotoxin. Mean systemic and pulmonary artery pressures, cardiac output, and hypoxic pressor responses were measured and compared in the two groups at 30, 60 , and $90 \mathrm{~min}$ after endotoxin. Arterial blood gas and white blood cell counts were obtained at the end of the experiment, $110 \mathrm{~min}$ after endotoxin injection. This dose of endotoxin was chosen to allow the study of hypoxic pulmonary vasoreactivity in a setting where the systemic blood pressure and cardiac output are not significantly depressed by endotoxin.

\section{In vitro assessment of lung injury}

Isolated perfused lungs. Male Sprague-Dawley rats (270-350 g) were anesthetized with pentobarbital and their lungs removed for extracorporeal perfusion as described by McMurtry et al. (28). Through a tracheal cannula the lungs were ventilated with a Harvard small animal respirator (model 646) at 55 breaths/min with 8-cm $\mathrm{H}_{2} \mathrm{O}$ inspiratory pressure and 2-3-cm $\mathrm{H}_{2} \mathrm{O}$ positive end-expiratory pressure. Inspired gas contained $21 \% \mathrm{O}_{2}, 5 \% \mathrm{CO}_{2}$, and $74 \% \mathrm{~N}_{2}$. A median sternotomy was then performed. After injection of $100 \mathrm{U}$ of heparin into the right ventricle, the pulmonary artery was cannulated and a second cannula placed in the left ventricle to collect effluent perfusate from the lungs. The lungs were perfused with a physiologic salt solution containing (in $\mathrm{mM}$ ): $119 \mathrm{NaCl}, 4.7 \mathrm{KCl}, 1.17$ $\mathrm{MgSO}_{4}, 22.6 \mathrm{NaHCO}_{3}, 1.18 \mathrm{KH}_{2} \mathrm{PO}_{4}, 1.6 \mathrm{CaCl}_{2}, 5.5$ glucose, 50 sucrose, and $4 \mathrm{~g} \%$ Ficoll (mol wt 70,000; Sigma Chemical Co.). The initial $50 \mathrm{ml}$ were discarded, leaving $50 \mathrm{ml}$ of cell- and plasma-free recirculating perfusate. Perfusion was maintained at a constant rate $(0.03 \mathrm{ml} / \mathrm{g}$ body wt $)$ using a model RL 175 peristaltic pump (Holter, Prussia, PA). Mean pulmonary artery inflow pressure was measured with a model P23AA transducer (Statham) and recorded on a recorder (Soltec Corp., Sun Valley, CA). The lungs were suspended by the tracheal cannula on a G1-15-300 force displacement transducer (Statham) for continuous measurement of lung weight which was recorded. The system was sensitive to a weight change of $0.1 \mathrm{~g}$.

Measurement of vascular permeability. We used a modification of the in vivo method described by Johnson and Ward (29) for assessment of pulmonary vascular permeability. At the beginning of lung perfusion, papaverine (final concentration $10^{-4} \mathrm{M}$, Sigma Chemical $\mathrm{Co}$.) was added to the perfusate reservoir to relax the pulmonary vasculature and equalize the perfusion pressures in the different experimental groups. This was done because differences in perfusion pressure may result in a difference of available vascular surface for the exchange of albumin and therefore affect the measurement of the leak index. $10 \mathrm{~min}$ after the addition of papaverine, $1 \mu \mathrm{Ci}$ of ${ }^{125} \mathrm{I}$-human serum albumin (Mallinckrodt, Inc., St. Louis, MO) was added to the perfusate reservoir and the lungs were perfused without any other intervention for the next $50 \mathrm{~min} .1 \mathrm{ml}$ of the perfusate was then collected and the lung switched to a nonrecirculating perfusion with $40 \mathrm{ml}$ of fresh, nonradioactive Ficoll perfusate. A second 1-ml aliquot of the perfusate was collected to document adequate wash out of the intravascular ${ }^{125} \mathrm{I}$-albumin. The lungs were dissected free and weighed and the radioactivity was measured (along with the two aliquots of perfusate) in a Auto-gamma scintillation spectrometer (Packard Instrument Co., Inc., Downers Grove, IL). The lung albumin 
leak index was calculated using the formula: Leak index $=$ (counts per minute in the lungs)/(counts per minute in $1.0 \mathrm{~g}$ of initial perfusate). The lungs were then placed in a Transite oven (Blue $\mathrm{M}$ Electronic, Blue Island, IL) at $60^{\circ} \mathrm{C}$ for $3 \mathrm{wk}$ and the dry weights were determined. Wet lung-to-body weight and wet-to-dry weight ratios were calculated. In some of the perfused lungs, microvascular pressure was measured using the double occlusion method (30) before the addition of papaverine.

Effect of PAF antagonists and neutropenia on endotoxin-induced lung injury. Five groups of rats $(n=6$ each) were studied: $(a)$ control rats received no pretreatment before lung removal and perfusion; $(b)$ endotoxin rats received $20 \mathrm{mg} / \mathrm{kg} S$. enteritidis lipopolysaccharide i.p. $90 \mathrm{~min}$ before lung removal; $(c)$ endotoxin/CV 3988 rats received $10 \mathrm{mg} / \mathrm{kg} \mathrm{CV}$ 3988 i.p. (in saline) $10 \mathrm{~min}$ before endotoxin injection; $(d)$ endotoxin/ RP rats received RP 48740 (Rhone-Poulenc, Centre de Recherches de Vitry, France) $10 \mathrm{mg} / \mathrm{kg}$ i.p. (in saline) $10 \mathrm{~min}$ before endotoxin; RP 48740, 3-(3-pyridyl)-1H,3H-pyrrolo(1,2-C)thiazole-7-carboxamide hydrochloride (31), is a PAF receptor antagonist structurally different from CV 3988; (e) endotoxin/SRI rats received SRI 63-441 $50 \mathrm{mg} / \mathrm{kg}$ i.p. (in saline) $30 \mathrm{~min}$ before endotoxin. $90 \mathrm{~min}$ after endotoxin injection, the rats were anesthetized with pentobarbital and the lungs were removed for perfusion.

In 15 additional rats, vinblastine $0.75 \mathrm{mg} / \mathrm{kg}$ was injected into the tail vein. Five of these rats received endotoxin $20 \mathrm{mg} / \mathrm{kg}$ i.p. 18-24 $\mathrm{h}$ after vinblastine and before the development of neutropenia. Six rats received endotoxin 4-5 d after vinblastine, when they were clearly neutropenic, and four rats received saline injection i.p. 4-5 d after vinblastine. $90 \mathrm{~min}$ after endotoxin or saline treatment, the rats were anesthetized with pentobarbital and $0.5 \mathrm{ml}$ of blood was removed from the right ventricle to document neutropenia before lung perfusion. Neutrophil counts were obtained by multiplying the total white blood cell count (from the Coulter counter, Coulter Electronics, Inc., Hialeah, FL) with the percent neutrophils obtained from manual differential on 100 cells.

Lungs were removed from each of the 45 rats and perfused according to the protocol described above. The mean pulmonary artery perfusion pressure at the beginning of the experiment (before addition of the papaverine), and the average perfusion pressure during ${ }^{125} \mathrm{I}$-albumin equilibration (the arithmetic mean of the perfusion pressures at the beginning and end of the ${ }^{125} \mathrm{I}$-albumin equilibration period) were recorded. Lung albumin leak index and lung wet-to-dry weight ratio were used as indicators of lung injury.

\section{Statistical analysis}

Values were expressed as mean \pm standard error of the mean. Means of several groups were compared by one-way analysis of variance using the method of Student-Newman-Keul to indicate the groups with significant differences (32). When group sizes were unequal, the method of Scheffe was used for multiple comparison (33). A paired $t$ test was used to compare the values from the same animal before and after an intervention. In comparing the changes in blood pressure from baseline in the four experimental groups, we used a nonparametric test for comparing time response curves described by Zerbe (34). The test was applied hierarchically as described by Petrondas and Gabriel (35) in order to compensate for the increased probability of detecting false differences when making multiple comparisons between the four study groups. A nonparametric $t$ test (Mann-Whitney test) was used for comparing differences in survival. Linear correlations were calculated using standard methods (32). Unless otherwise stated, differences were considered significant when $P<0.05$.

\section{Results}

\section{Measurements of PAF}

Within 20 min after i.p. endotoxin injection, the levels of PAF in blood (Fig. $1 A$ ) and whole lung homogenate (Fig. $1 B$ ) were increased over control values. Blood PAF increased threefold from $4.3 \pm 1.3$ to $13.7 \pm 2.0 \mathrm{ng} / \mathrm{ml}$ (mean \pm SEM, $P<0.01$ ), whereas lung PAF increased almost 10 -fold, from $32.3 \pm 4.9$ to
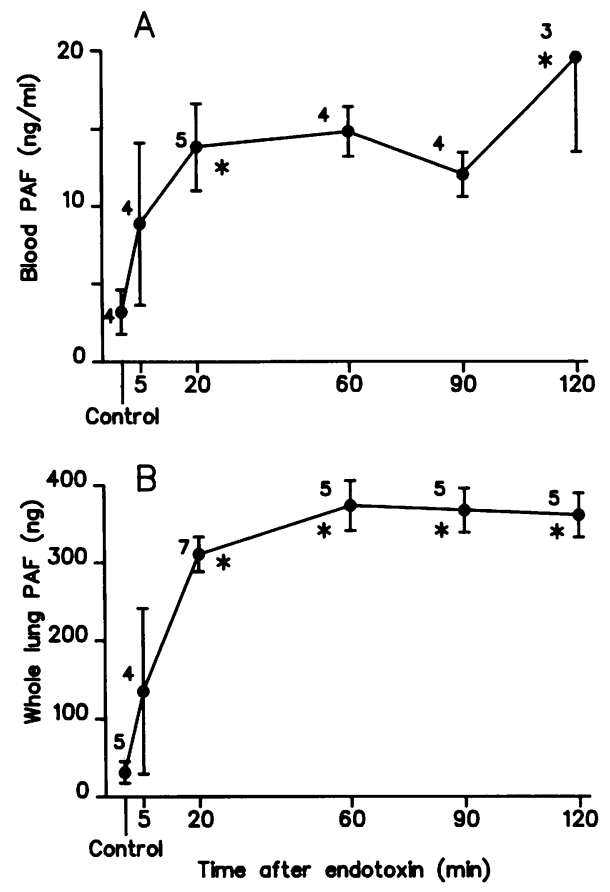

Figure 1. (A) Blood PAF levels after endotoxin treatment in rats. Shown are the means (and standard errors) of blood PAF values in different groups of rats after i.p. injection of $20 \mathrm{mg} / \mathrm{kg}$. S. enteritidis endotoxin. The numbers indicate the number of animals in each group. ${ }^{*} P<0.05$ from control values. $(B)$ Lung PAF levels after endotoxin treatment.

$312.3 \pm 19.6 \mathrm{ng}(P<0.01)$. The increases in PAF appeared to reach a plateau which persisted for up to $2 \mathrm{~h}$ in both blood and lung.

In contrast, lung lavage fluid obtained $90 \mathrm{~min}$ after endotoxin treatment showed no increase in PAF over control values (control $1.0 \pm 0.6$, endotoxin $1.2 \pm 0.4 \mathrm{ng} /$ lavage). Because albumin binds to PAF and is used experimentally as a carrier for PAF (19), we wondered whether addition of albumin to the lavage fluid would enhance the recovery of PAF. We found that addition of $0.25 \%$ bovine serum albumin to the lavage fluid did not improve the recovery of PAF (control $1.0 \pm 0.2$, endotoxin $1.6 \pm 0.4 \mathrm{ng} /$ lavage). The saline lavage fluid from the calcium ionophore-treated lungs contained $260 \mathrm{ng}$ of PAF, indicating that under the condition of maximal stimulation and lung injury, PAF could be recovered from the alveolar space.

Because the kidney may synthesize PAF (36), we also measured PAF levels in kidney homogenates at various time points after endotoxin. Kidneys from control rats contained $2.2 \pm 0.3$ ng of PAF (mean \pm SEM, $n=4$ ). Only the PAF values $90 \mathrm{~min}$ after endotoxin $(12.8 \pm 2.2 \mathrm{ng}, n=4)$ were significantly increased over control. Both the baseline and post-endotoxin values of PAF in the kidneys were markedly lower than those found in the lung, although the degree of enhancement by endotoxin was similar in the two organs.

Vinblastine-treated rats showed markedly lower total neutrophil counts on days 4 and 5 compared with control animals (58 \pm 54 vs. $1,883 \pm 574$ per $\mu \mathrm{l}, P<0.01, n=6$ each group). There was no significant difference in hematocrit $(37.2 \pm 1.2$ vs. $39.1 \pm 1.9$ in controls) and platelet counts $(986,000 \pm 80,000$ vs. $1,090,000 \pm 77,000$ per $\mu$ in controls) between the vinblastinetreated rats and controls. 
In the study with neutropenic rats, which was performed several months after the initial set of PAF measurements, endotoxin caused nearly a threefold increase in lung PAF levels and neutropenia failed to reduce the increase in lung PAF levels after endotoxin (Fig. 2). The five neutropenic rats (not treated with endotoxin) had lung PAF values (174 $\pm 43 \mathrm{ng}$ ) similar to controls (115 $\pm 8 \mathrm{ng}$ ). In this second study the PAF values in the control lungs were significantly higher than the control values in the first study (Fig. $1 \mathrm{~B}$ ), although the lung PAF levels in the endotoxin-treated rats were similar in the two studies.

\section{Hemodynamic studies}

EFFECT OF CV 3988 ON PAF-INDUCED

HEMODYNAMIC CHANGES

Bolus injection of $10 \mathrm{ng}$ of PAF into the jugular vein during hypoxic vasoconstriction resulted in a rapid and transient decrease in both mean aortic and pulmonary artery pressure (Fig. 3). The maximal decrease was observed at $1 \mathrm{~min}$ after injection and averaged $23 \pm 2 \%$ of the baseline aortic pressure and $35 \pm 5 \%$ of the hypoxic pressor response $(n=7)$. Injection of $10 \mathrm{ng}$ of PAF during normoxia in two rats resulted in a similar decrease in mean aortic pressure but the mean pulmonary artery pressure was not changed (data not shown), perhaps because the normal pulmonary vasculature is nearly maximally dilated.

In three rats, repeated injections of PAF at intervals of 20$30 \mathrm{~min}$ resulted in decreases in aortic and pulmonary pressures similar to that shown in Fig. 3, thus indicating that tachyphylaxis to this dose of PAF did not occur. Administration of CV 3988 (10 mg/kg i.v.) over 1-2 min did not affect the mean aortic and pulmonary artery pressures or the subsequent pulmonary pressor responses to hypoxia. After CV 3988, the systemic and pulmonary hypotensive effects of $10 \mathrm{ng}$ of PAF were significantly blocked (Fig. 3). This PAF-antagonistic effect of CV 3988 persisted for at least $2 \mathrm{~h}$. In two rats, despite pretreatment of CV 3988 , bolus injection of large dose of PAF (100 ng) caused hypotension (data not shown), indicating that the blockade of PAF receptor by CV 3988 could be overcome with higher PAF concentration.

\section{EFFECT OF CV 3988 ON ENDOTOXIN-INDUCED}

HEMODYNAMIC CHANGES

Baseline hemodynamic data. All rats $(n=24)$ appeared healthy at the beginning of the hemodynamic study with a (mean \pm SEM)

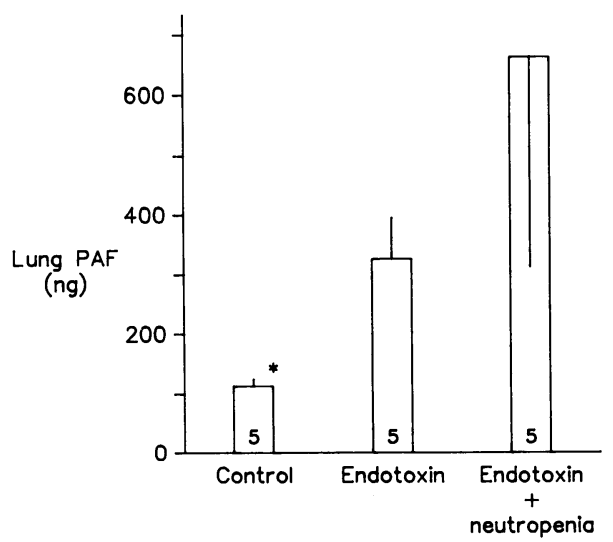

Figure 2. Effect of neutropenia on endotoxin-induced increase in lung PAF levels. Neutropenia was induced by i.v. vinblastine $0.75 \mathrm{mg} / \mathrm{kg} 4$ $\mathrm{d}$ before the endotoxin study. ${ }^{*} P<0.05$ from endotoxin alone.

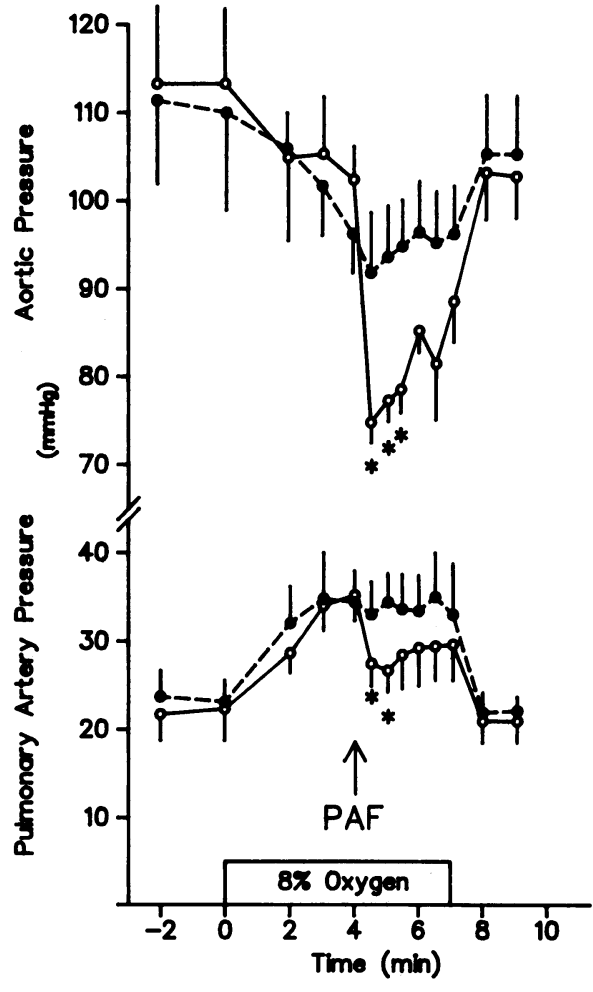

Figure 3. Effect of CV 3988 on PAF-induced hypotension. Data shown represent means (and standard errors) of mean aortic and pulmonary artery pressures in four rats before (open circles) and after (solid circles) $10 \mathrm{mg} / \mathrm{kg}$ of CV 3988 i.v. PAF (10 ng) was given as an i.v. injection during the fourth minute of the hypoxic challenge. ${ }^{*} P$ $<0.05$ compared with corresponding values after CV 3988.

heart rate of $420 \pm 14 / \mathrm{min}$, aortic pressure $110.2 \pm 2.2 \mathrm{mmHg}$, pulmonary artery pressure $21.0 \pm 0.5 \mathrm{mmHg}$, cardiac output $0.125 \pm 0.009 \mathrm{liter} / \mathrm{min}$, and baseline hypoxic pressor response (average of the second and third hypoxic responses) of $12.5 \pm 0.9$ $\mathrm{mmHg}$. Mean arterial blood gas values on room air for the whole group $(n=24)$ were $\mathrm{pH} 7.51 \pm 0.01, \mathrm{PCO}_{2} 29.3 \pm 0.8$ torr, and $\mathrm{PO}_{2} 71.8 \pm 1.4$ torr, and in four animals during hypoxic challenges with $8 \% \mathrm{O}_{2}$ were $\mathrm{pH} 7.68 \pm 0.01, \mathrm{PCO}_{2} 15.7 \pm 2.2$ torr, and $\mathrm{PO}_{2}$ $28.8 \pm 1.9$ torr.

Effect of endotoxin. Table I shows the effect of endotoxin on systemic and pulmonary hemodynamics and hypoxic pressor response in awake rats. Control animals showed no significant change in the hemodynamic values and hypoxic pressor responses over time. In endotoxin-treated animals, marked systemic hypotension and decreased cardiac outputs developed 30 and $60 \mathrm{~min}$ after endotoxin administration. $60 \mathrm{~min}$ after endotoxin, the mean systemic blood pressure and the cardiac output were $76 \%$ and $50 \%$ of the pre-endotoxin values, respectively. The systemic vascular resistance increased over this period. In endotoxin-treated rats, mean pulmonary artery pressure decreased and total pulmonary resistance increased over time. The pressor response to $8 \%$ oxygen was markedly depressed by endotoxin $(31 \%$ and $28 \%$ of the baseline value at 30 and $60 \mathrm{~min}$ after endotoxin).

Table II shows the effect of endotoxin on arterial blood gas values, white blood cell count, and hematocrit. Endotoxintreated rats developed hyperventilation, a decrease in the calculated alveolar-arterial gradient for oxygen and a significant 
Table I. Effect of Endotoxin on Hemodynamic Variables and Hypoxic Pressor Response

\begin{tabular}{|c|c|c|c|c|}
\hline Variable & Group & Baseline & $30 \mathrm{~min}$ & $60 \min$ \\
\hline \multirow{2}{*}{ Heart rate $\left(\mathrm{min}^{-1}\right)$} & $\mathrm{C}$ & $377 \pm 17$ & $385 \pm 17$ & $387 \pm 14$ \\
\hline & $\mathrm{E}$ & $394 \pm 20$ & $435 \pm 17$ & $438 \pm 23$ \\
\hline \multirow[t]{2}{*}{ Mean systemic blood pressure $(\mathrm{mmHg})$} & $\mathrm{C}$ & $120 \pm 3$ & $117 \pm 5$ & $117 \pm 6$ \\
\hline & E & $109 \pm 3$ & $95 \pm 5^{* \S}$ & $83 \pm 5^{\ddagger \S}$ \\
\hline \multirow[t]{2}{*}{ Mean pulmonary artery pressure $(\mathrm{mmHg})$} & $\mathrm{C}$ & $20.7 \pm 1.1$ & $21.1 \pm 1.5$ & $21.4 \pm 0.6$ \\
\hline & $\mathrm{E}$ & $21.0 \pm 0.9$ & $18.5 \pm 0.8^{* \S}$ & $17.9 \pm 0.7^{* \S}$ \\
\hline \multirow[t]{2}{*}{ Cardiac output (liter/min) } & $\mathrm{C}$ & $0.138 \pm 0.019$ & $0.119 \pm 0.012$ & $0.118 \pm 0.012$ \\
\hline & $\mathrm{E}$ & $0.142 \pm 0.021$ & $0.078 \pm 0.016^{\ddagger}$ & $0.071 \pm 0.018$ \\
\hline \multirow[t]{2}{*}{ Systemic vascular resistance $(\mathrm{mmHg} \cdot \mathrm{min} /$ liter $)$} & $\mathrm{C}$ & $932 \pm 125$ & $1025 \pm 113$ & $1030 \pm 110$ \\
\hline & $\mathrm{E}$ & $915 \pm 165$ & $1821 \pm 610^{*}$ & $2390 \pm 1108$ \\
\hline \multirow[t]{2}{*}{ Total pulmonary resistance $(\mathrm{mmHg} \cdot \mathrm{min} /$ liter $)$} & $\mathrm{C}$ & $166 \pm 25$ & $191 \pm 26$ & $187 \pm 22$ \\
\hline & E & $175 \pm 35$ & $363 \pm 123^{*}$ & $520 \pm 245^{*}$ \\
\hline \multirow[t]{2}{*}{ Hypoxic pressor response $(\mathrm{mmHg})$} & $\mathrm{C}$ & $15.2 \pm 1.3$ & $18.6 \pm 2.5$ & $20.2 \pm 2.5$ \\
\hline & $\mathrm{E}$ & $13.6 \pm 2.2$ & $4.2 \pm 1.4^{\ddagger \S}$ & $3.8 \pm 1.2^{\ddagger \S}$ \\
\hline
\end{tabular}

Hypoxic pressor response was calculated as the difference between the maximal pulmonary artery pressure during 5 min of hypoxic challenge $\left(8 \% \mathrm{O}_{2}\right)$ and the pulmonary artery pressure immediately before hypoxia. Measurements were obtained at time 0,30 , and 60 min. Endotoxin group received $20 \mathrm{mg} / \mathrm{kg}$ of $S$. enteritidis endotoxin i.p. at time 0 . C, control $(n=5)$; E, endotoxin-treated animals $(n=7)$. ${ }^{*} P<0.05$ compared with baseline value. ${ }^{\ddagger} P<0.01$ compared with baseline value. ${ }^{\S} P<0.05$ compared with the control value at the corresponding time point.

metabolic acidosis. Leukopenia was observed after endotoxin and there was a trend for the hematocrit to increase. Control animals showed a significant decrease in hematocrit over time perhaps because of a combination of blood sampling and hemodilution from saline flushes given to keep the catheters patent. The platelet counts are not reported here because a large variation in platelet counts was observed in control animals, perhaps due to the use of heparin to keep the catheters patent.

Effect of CV 3988. Treatment with CV 3988 (in 30\% ethanol, which served as the vehicle) or ethanol alone resulted in mean

Table II. Effect of Endotoxin on Arterial Blood Gas Values, White Blood Cell Count, and Hematocrit

\begin{tabular}{|c|c|c|c|}
\hline & Group & Baseline & $80 \mathrm{~min}$ \\
\hline \multirow[t]{2}{*}{ pH } & $\mathrm{C}$ & $7.51 \pm 0.01$ & $7.53 \pm 0.01$ \\
\hline & $\mathrm{E}$ & $7.49 \pm 0.01$ & $7.39 \pm 0.03^{\ddagger \S}$ \\
\hline \multirow{2}{*}{$\mathrm{PCO}_{2}$ (torr) } & $\mathrm{C}$ & $25.5 \pm 1.3$ & $24.2 \pm 2.0$ \\
\hline & $\mathrm{E}$ & $28.0 \pm 2.0$ & $16.9 \pm 2.8^{\ddagger}$ \\
\hline \multirow[t]{2}{*}{$\mathrm{PO}_{2}$ (torr) } & $\mathrm{C}$ & $71.8 \pm 2.0$ & $72.6 \pm 1.5$ \\
\hline & $\mathrm{E}$ & $71.6 \pm 1.5$ & $95.1 \pm 2.6^{\ddagger \S}$ \\
\hline \multirow[t]{2}{*}{$\mathrm{DA}-\mathrm{aO}_{2}$ (torr) } & $\mathrm{C}$ & $18.4 \pm 3.3$ & $19.2 \pm 1.7$ \\
\hline & $\mathrm{E}$ & $15.4 \pm 3.1$ & $5.7 \pm 3.0^{\ddagger \S}$ \\
\hline \multirow{2}{*}{$\begin{array}{l}\text { White blood cell count } \\
\left(\times 10^{3} / \mu l\right)\end{array}$} & $\mathrm{C}$ & $4.6 \pm 1.3$ & $5.7 \pm 2.2$ \\
\hline & $\mathrm{E}$ & $5.8 \pm 1.1$ & $1.8 \pm 0.3^{\ddagger \S}$ \\
\hline \multirow[t]{2}{*}{ Hematocrit (\%) } & $\mathrm{C}$ & $42.7 \pm 0.8$ & $39.7 \pm 1.3^{*}$ \\
\hline & $\mathrm{E}$ & $41.3 \pm 2.0$ & $43.1 \pm 1.1$ \\
\hline
\end{tabular}

$\mathrm{C}$, control; $\mathrm{DA}-\mathrm{aO}_{2}$, alveolar-arterial gradient for oxygen, calculated as $122-\left(\mathrm{PCO}_{2} / 0.8\right)-\mathrm{PO}_{2} ; \mathrm{E}$, endotoxin-treated animals. (Symbols are the same as in Table I.) plasma ethanol levels of $62 \pm 7 \mathrm{mg} / \mathrm{dl} 80 \mathrm{~min}$ after endotoxin ( =4). CV 3988 significantly protected against the endotoxininduced systemic hypotension (Fig. 4), whereas the blood pressure in ethanol vehicle-treated rats was not different from that of rats treated with endotoxin alone. Although the difference in blood pressure values between the endotoxin/CV 3988 and endotoxin/ethanol groups did not reach statistical significance, in a subsequent group of five rats the protective effect of CV 3988 in normal saline against endotoxin-induced hypotension was almost identical to that of CV 3988 in ethanol $(-8 \pm 4 \%$ at 30

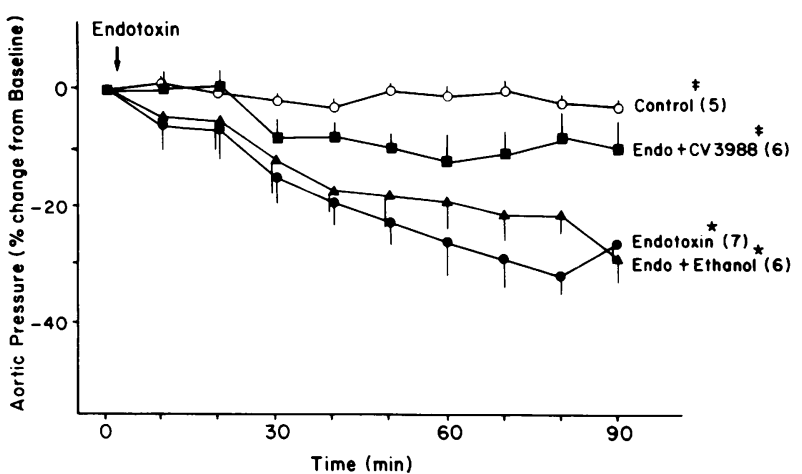

Figure 4. Effects of CV 3988 on endotoxin-induced hypotension. The means $\pm \mathrm{SE}$ of aortic pressures (expressed as percent change from preendotoxin baseline) are plotted for control (open circles), endotoxin (solid circles), endotoxin/ethanol (solid triangles), and endotoxin/CV 3988 (solid squares) animals. Endotoxin $(20 \mathrm{mg} / \mathrm{kg}$ i.p.) was given at time 0 . CV $3988(10 \mathrm{mg} / \mathrm{kg}$ in $30 \%$ ethanol) or an equal volume of $30 \%$ ethanol was given i.v. $10 \mathrm{~min}$ before endotoxin. Half of the initial dose of CV 3988 or ethanol was given $1 \mathrm{~h}$ later. Data were analyzed using a nonparametric time-response curve analysis (see statistical analysis). ${ }^{*} P<0.05$ compared with control group; $\ddagger P<0.05$ compared with endotoxin group. 
min and $-15 \pm 6 \%$ at $60 \mathrm{~min})$. Thus, CV 3988 alone was active against endotoxic shock.

The effects of CV 3988 and ethanol on cardiac output and pulmonary hemodynamics are shown on Fig. 5. Both CV 3988 and the ethanol vehicle alone significantly protected against the decrease in mean pulmonary artery pressure and cardiac output caused by endotoxin. Thus these effects were attributable to the action of ethanol. The cardiac outputs at 30 and $60 \mathrm{~min}$ for the endotoxin group were $54 \pm 8 \%$ and $46 \pm 8 \%$ of the baseline value, whereas those for endotoxin/ethanol group were $87 \pm 12 \%$ and $80 \pm 12 \%$. Corresponding cardiac output results for the CV 3988 infusion (in normal saline) group were $71 \pm 10 \%$ and $74 \pm 14 \%$ of the baseline value. Thus CV 3988 alone had a mild (but nonsignificant) protective effect on the cardiac output depression. The increase in total pulmonary resistance after endotoxin was attenuated by both CV 3988 and ethanol. However, because of the large scatter in the data, there was no significant difference between the four groups. The changes in systemic vascular resistance (not shown) were similar in pattern as that for total pulmonary resistance.

CV 3988, but not the ethanol vehicle, protected against the decrease in hypoxic pressor response $30 \mathrm{~min}$ after endotoxin treatment (Fig. 6). The difference between endotoxin and endotoxin/CV 3988 groups at 60 min did not reach statistical significance. In the rats treated with CV 3988 infusion, the hypoxic pressor responses at baseline, 30 and $60 \mathrm{~min}$ after endotoxin were $10.4 \pm 0.4,9.6 \pm 2.7$, and $11.0 \pm 4.7 \mathrm{mmHg}$. Thus CV 3988 infusion also protected the rats from the endotoxin-induced decreases in pulmonary pressor response to hypoxia.

Fig. 7 shows that CV 3988 did not prevent the leukopenia, hypocapnia, or metabolic acidosis after endotoxin. Fig. 8 shows the survival data for the five groups of animals. All of the en-

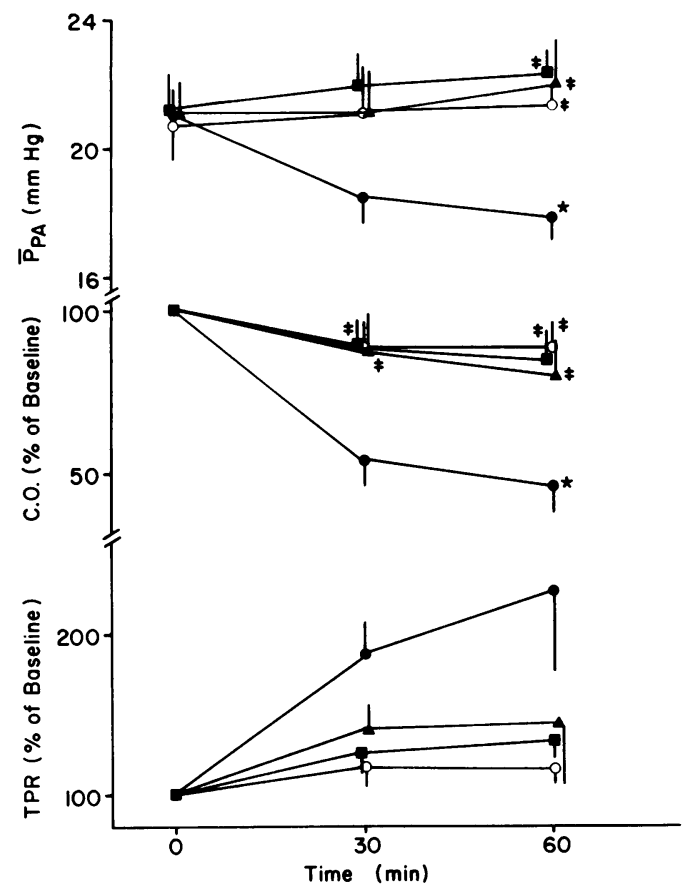

Figure 5. Effect of CV 3988 on endotoxin-induced changes in cardiac output and pulmonary hemodynamics. Means \pm SE of mean pulmonary artery pressure ( $\overline{\mathrm{P}}_{\mathrm{PA}}$, top panel), cardiac output (C.O., middle panel), and total pulmonary resistance (TPR, bottom panel) are shown. Endotoxin was given at time 0. Symbols are as in Fig. 4.

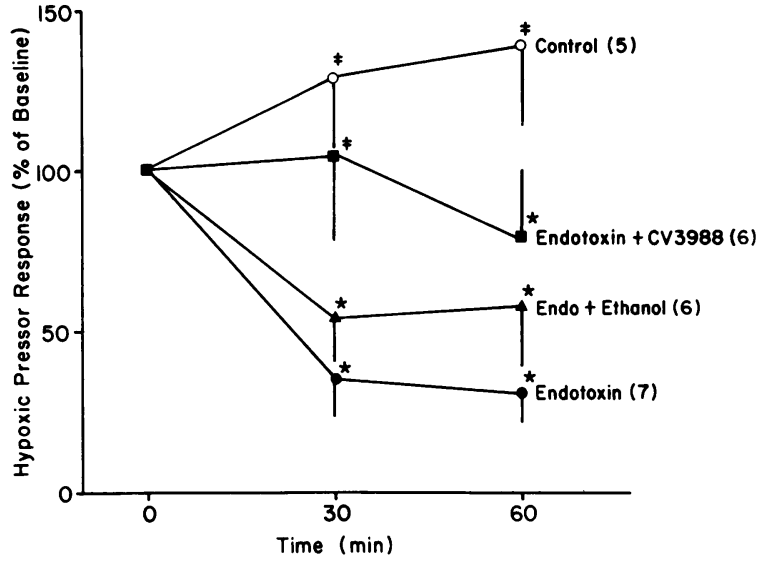

Figure 6. Effect of CV 3988 on hypoxic pressor response. Symbols are as in Fig. 4.

dotoxin treated rats died within $12 \mathrm{~h}$ after the endotoxin injection whereas two of the endotoxin/CV 3988 group survived to $7 \mathrm{~d}$. The number of animals surviving $>24 \mathrm{~h}$ in each group were five of five control, zero of six endotoxin, two of six endotoxin/ ethanol, and four of six endotoxin/CV 3988. An additional three of five animals in the CV 3988 infusion group survived past 24 $h$. The median survival for the endotoxin $(n=6)$, endotoxin/ ethanol $(n=6)$, and endotoxin/CV 3988 (combined with the infusion group, $n=11$ ) groups were $5,5.5$, and $32 \mathrm{~h}$. Using a nonparametric $t$ test (Mann-Whitney), the prolongation of mean survival time by CV 3988 was not statistically significant.

EFFECT OF SRI 63-441 ON ENDOTOXIN-INDUCED DEPRESSION OF HYPOXIC PULMONARY VASOCONSTRICTION

During the $90 \mathrm{~min}$ after the injection of a lower dose endotoxin ( $2 \mathrm{mg} / \mathrm{kg}$ ), no significant systemic hypotension was observed (data not shown). In addition, all five rats survived for over $4 \mathrm{~d}$ after endotoxin treatment. The pulmonary hemodynamic changes are shown in Fig. 9. Low-dose endotoxin caused no significant change in the pulmonary artery pressure and cardiac output. Total pulmonary resistance was significantly elevated only at the 90-min time point. Pretreatment with SRI 63-441 5 min before endotoxin injection allowed the rats to achieve significantly higher cardiac output and pulmonary artery pressure 30 min later. Despite the minimal disturbance of resting hemodynamics, this dose of endotoxin caused marked and persis-

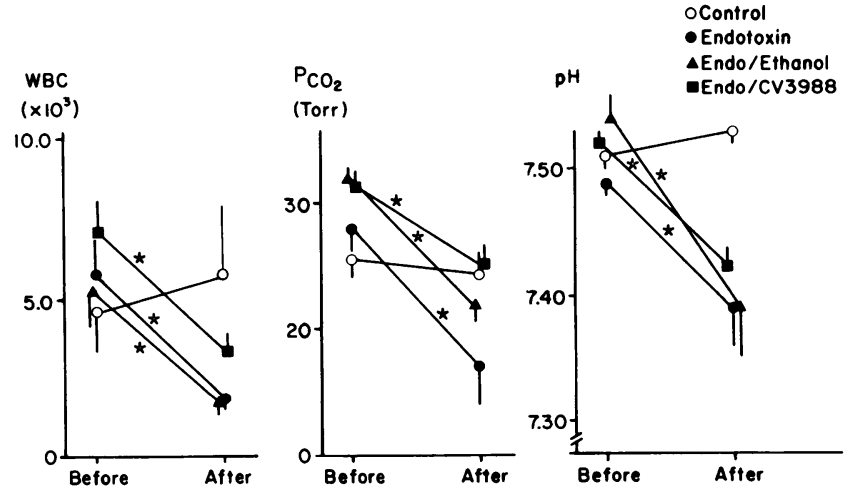

Figure 7. Effect of CV 3988 on white blood cell counts (WBC), $\mathrm{PCO}_{2}$, and $\mathrm{pH} .{ }^{*} P<0.05$ by paired $t$ test. 


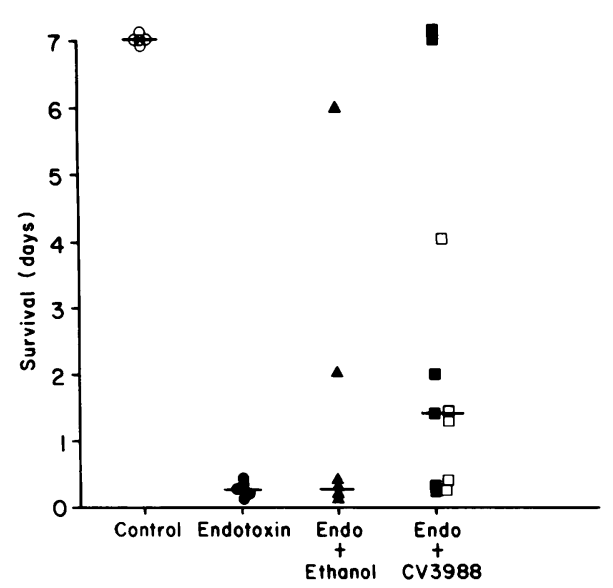

Figure 8. Survival data after acute hemodynamic study. In addition to the four groups shown in the previous figures, the data for endotoxin/ CV 3988 infusion (open squares) animals are shown. Horizontal bars indicate the median survival for each group. The two CV 3988 treatment groups are combined for the calculation of median survival.

tent depression of hypoxic vasoreactivity (Fig. 10). Pretreatment with SRI 63-441 significantly improved the hypoxic pressor responses in endotoxin-treated rats (Fig. 10). Like CV 3988, SRI 63-441 failed to block the leukopenia or the hypocapnia following endotoxin (white blood cells $2.7 \pm 0.4 \times 10^{3}$ and $\mathrm{PCO}_{2} 25.1 \pm 1.8$ torr in endotoxin controls and white blood cells $2.9 \pm 0.3 \times 10^{3}$ and $\mathrm{PCO}_{2} 23.8 \pm 2.5$ torr in endotoxin + SRI 63-441 group), although the arterial blood $\mathrm{pH}$ was significantly higher in the SRI 63-441-treated animals $(7.51 \pm 0.02$ vs. $7.44 \pm 0.02$ in endotoxin controls).

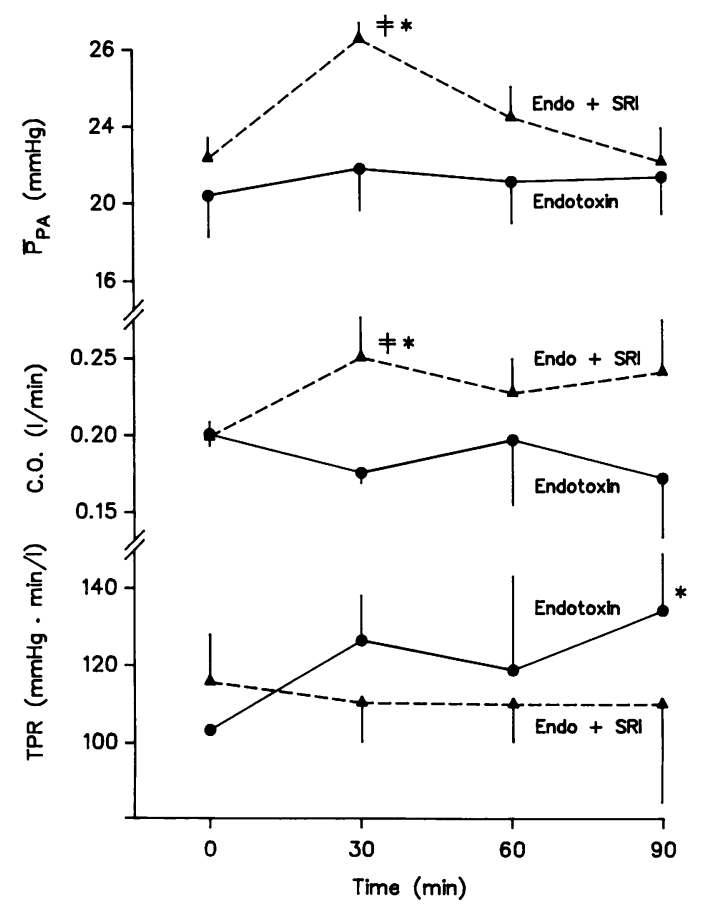

Figure 9. Effect of SRI 63-441 on low-dose endotoxin-induced changes in cardiac output (C.O.) and pulmonary hemodynamics (TPR, total pulmonary resistance; $\overline{\mathrm{P}}_{\mathrm{PA}}$, mean pulmonary artery pressure). Endotoxin ( $2 \mathrm{mg} / \mathrm{kg}$ i.v.) was given at time 0 and SRI 63-441 $(20 \mathrm{mg} / \mathrm{kg})$ or normal saline was infused $5 \mathrm{~min}$ before endotoxin. 1 , liter.

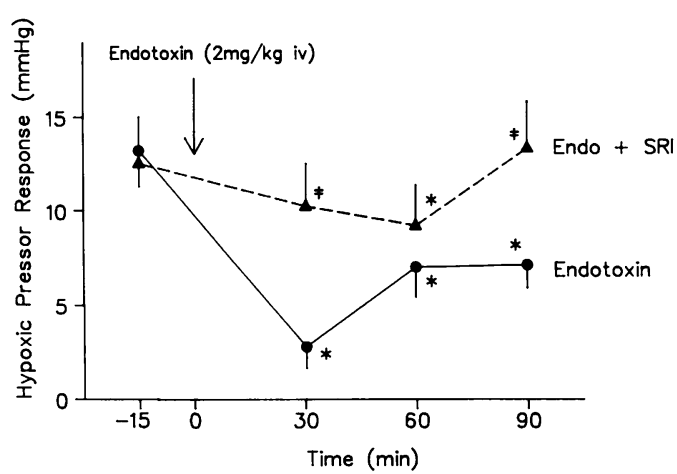

Figure 10. Effect of SRI 63-441 on hypoxic pressor responses after low-dose endotoxin. Hypoxic pressor response is calculated as the difference between the mean pulmonary artery pressures at room air and while breathing $8 \%$ oxygen. ${ }^{*} P<0.05$ compared with baseline hypoxic pressor response before endotoxin. $¥ P<0.05$ compared with endotoxin alone.

\section{In vitro assessment of lung injury}

Before lung removal, all endotoxin-treated animals appeared ill with decreased motor activities, ruffled furs, and diarrhea. Neither the PAF receptor antagonists nor neutropenia appeared to ameliorate these clinical signs. Lungs from endotoxin-treated rats had higher initial perfusion pressure than that from control rats, although the difference did not reach statistical significance (Table III). Using the double-occlusion method, the microvascular pressures were found to be similar in the lungs from endotoxin-treated and control rats $(1.8 \pm 0.2$ vs. $2.1 \pm 0.2 \mathrm{mmHg}, n$ $=6$ each).

Fig. 11 shows the calculated leak index values for the perfused lungs from rats treated with endotoxin and PAF antagonists.
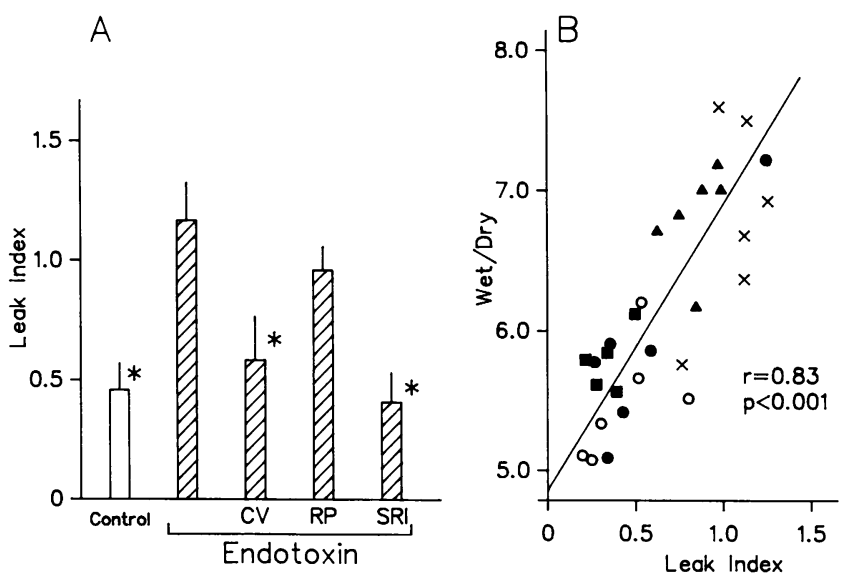

Figure 11. $(A)$ Effect of PAF antagonists on pulmonary vascular permeability changes after endotoxin. CV $3988(10 \mathrm{mg} / \mathrm{kg}$ i.p. $)$ and RP $48740(10 \mathrm{mg} / \mathrm{kg}$ i.p.) were administered $10 \mathrm{~min}$ before endotoxin (20 $\mathrm{mg} / \mathrm{kg}$ i.p.), and SRI $63-441(50 \mathrm{mg} / \mathrm{kg}$ i.p.) was administered $30 \mathrm{~min}$ before endotoxin. The lungs were isolated $90 \mathrm{~min}$ after endotoxin treatment and perfused with physiologic salt solution containing ${ }^{125} \mathrm{I}-$ albumin. Leak index $=$ (counts per minute in lungs)/(counts per minute in $1.0 \mathrm{~g}$ of perfusate). ${ }^{*} P<0.05$ from endotoxin. $n=6$ in each group. $(B)$ Correlation between lung wet wt-to-dry wt ratio and leak index. Individual values for (open circles) control, $(X)$ endotoxin, (solid circles) endotoxin/CV 3988, (solid triangles) endotoxin/RP 48740, and (solid squares) endotoxin/SRI 63-441 animals are shown. 
Perfused lungs from endotoxin-treated rats showed significantly increased extravascular albumin leakage over that from control animals $(1.13 \pm 0.08$ vs. $0.46 \pm 0.09, P<0.01)$. This increase was blocked by CV 3988 (leak index $0.57 \pm 0.15$ ) and SRI 63-441 (leak index 0.39 \pm 0.04 ). Although in the RP 48740-pretreated rats, the albumin leak index $(0.99 \pm 0.05)$ was somewhat lower than that from endotoxin-treated rats, the difference was not statistically significant. Similarly, both CV 3988 and SRI 63441 blocked the increases in the lung wet-to-dry weight ratios caused by endotoxin (Table III). These differences in the leak index and lung weights were observed despite similar average perfusion pressures in the five groups of perfused lungs with the exception of the slightly higher perfusion pressure in the endotoxin/SRI group. For the entire group of 30 animals, there was an excellent correlation between the wet/dry weight ratio of the lungs at the end of the perfusion and the albumin leak index (Fig. 11), suggesting that endotoxin-damaged lungs were equally susceptible to the extravascular accumulation of both water and protein.

Table IV shows the effect of vinblastine-induced neutropenia on endotoxin-induced lung injury. $4 \mathrm{~d}$ after vinblastine treatment, when the circulating neutrophil count was markedly reduced, endotoxin failed to cause an increase in either the extravascular accumulation of ${ }^{125} \mathrm{I}$-albumin or water in the perfused lungs. The protection against endotoxin-induced lung injury can be attributed to the neutropenic effect of vinblastine in that vinblastine-treated rats (1 d) were still susceptible to endotoxin injury before the development of neutropenia.

\section{Discussion}

The principal findings of this study are: $(a)$ there were marked and persistent increase in blood and lung PAF levels after endotoxemia in rats; (b) the PAF receptor blocker, CV 3988, at a dose that effectively blocked the systemic and pulmonary hypotensive effect of PAF, attenuated the systemic hypotension and partially restored the pulmonary hypoxic pressor response that was impaired by endotoxin; $(c)$ another PAF receptor antagonist, SRI 63-441, prevented the decrease in pulmonary hypoxic pressure response after low-dose endotoxin; and $(d)$ both CV 3988 and SRI 63-441 prevented the endotoxin-induced increase in pulmonary vascular leakage of albumin. Together, these

Table III. Effect of PAF Antagonists on Endotoxin-induced Changes in Pulmonary Artery Pressures and Water Content of Perfused Rat Lungs

\begin{tabular}{llllll}
\hline Groups & $n$ & Body wt & $\mathrm{PP}_{\mathrm{T}}=0$ & $\mathrm{PP}_{\mathrm{avz}}$ & Wet wt/dry wt \\
\hline & & $g$ & $m m H g$ & $m m H g$ & \\
Control & 6 & $315 \pm 10$ & $5.8 \pm 0.3$ & $4.8 \pm 0.4$ & $5.45 \pm 0.17^{\ddagger}$ \\
Endotoxin & 6 & $321 \pm 11$ & $6.8 \pm 0.3$ & $5.7 \pm 0.2$ & $6.67 \pm 0.28^{*}$ \\
Endo + CV 3988 & 6 & $307 \pm 13$ & $6.0 \pm 0.3$ & $5.3 \pm 0.3$ & $5.79 \pm 0.29^{\ddagger}$ \\
Endo + RP 48740 & 6 & $295 \pm 2$ & $5.8 \pm 0.3$ & $5.4 \pm 0.2$ & $6.74 \pm 0.14^{*}$ \\
Endo + SRI 63-441 & 6 & $305 \pm 10$ & $7.6 \pm 0.4^{*}$ & $6.7 \pm 0.3^{*}$ & $5.79 \pm 0.28^{\ddagger}$
\end{tabular}

Values given are means $\pm S E$ for the five groups of rats. $P P_{T}=0$, initial perfusion pressure at the beginning of the lung perfusion; $\mathrm{PP}_{\mathrm{avg}}$, average perfusion pressure during the ${ }^{125} \mathrm{I}$-albumin equilibration period.

* $P<0.05$ compared with control animals.

${ }^{\ddagger} P<0.05$ compared with endotoxin animals.
Table IV. Effect of Vinblastine-induced Neutropenia on Endotoxin Lung Injury

\begin{tabular}{|c|c|c|c|c|}
\hline Groups & $n$ & PMN & Leak index & Wet wt/dry wt \\
\hline & & $\mu l^{-1}$ & & \\
\hline Control & 6 & $1,945 \pm 482^{\ddagger}$ & $0.46 \pm 0.09^{\ddagger}$ & $5.45 \pm 0.17^{\ddagger}$ \\
\hline Endotoxin & 6 & $581 \pm 142^{*}$ & $1.13 \pm 0.08^{*}$ & $6.67 \pm 0.28^{*}$ \\
\hline $\begin{array}{r}\text { Vinblastine } 1 \mathrm{~d} \\
+ \text { endotoxin }\end{array}$ & 5 & $822 \pm 264^{* 8}$ & $1.06 \pm 0.05^{*}$ & $7.82 \pm 0.12^{* \neq}$ \\
\hline $\begin{array}{r}\text { Vinblastine } 4 \mathrm{~d} \\
+ \text { endotoxin }\end{array}$ & 6 & $5 \pm 4^{* \ddagger}$ & $0.52 \pm 0.08^{\ddagger}$ & $5.95 \pm 0.16^{\ddagger}$ \\
\hline Vinblastine $4 \mathrm{~d}$ & 4 & $73 \pm 48^{* *}$ & $0.49 \pm 0.06^{\ddagger}$ & $6.06 \pm 0.21^{*}$ \\
\hline
\end{tabular}

Values given are means $\pm \mathrm{SE}$ of the numbers of circulating polymorphonuclear leukocytes (PMN), the extravascular ${ }^{125}$ I-albumin leak index, and the wet wt-to-dry wt ratios of the perfused lungs. The PMN count was determined using blood obtained by right ventricular aspiration before lung isolation ( $90 \mathrm{~min}$ after i.p. administration of saline or endotoxin). The leak index and wet wt/dry wt ratio were calculated as described in the Methods. Vinblastine was injected into the tail vein either $1 \mathrm{~d}$ (nonneutropenic) or $4 \mathrm{~d}$ before endotoxin treatment.

* $P<0.05$ compared with control groups.

${ }^{\ddagger} P<0.05$ compared with endotoxin treatment alone.

${ }^{\S}$ Based on $n=3$. In a separate group of rats $(n=4)$ the neutrophil counts $1 \mathrm{~d}$ after vinblastine injection (without endotoxin) were $2,050 \pm 366 \times \mu \mathrm{l}^{-1}$.

findings suggest that PAF plays an important role in endotoxin shock and in endotoxin-induced lung injury in rats.

Our finding of an early increase in blood PAF levels after endotoxemia is qualitatively similar to that reported by Doebber et al. (10). However, the persistence of a high level of PAF throughout the 2-h period of observation has not been observed previously and indicates either a high level of continued production or a marked depression in the activity of the plasma acetylhydrolase that normally degrades PAF (17). Yet, in our study, the increase in PAF over baseline values is even more impressive in the lung than in the blood. This might suggest either that the primary source of PAF production is in the lung or that the cells that produce PAF are sequestered in the lung after endotoxemia. Because neutrophils are sequestered in the lung after endotoxin administration (37), neutrophils could contribute to the marked increase in the lung PAF concentration found after endotoxemia (38). However, our finding that neutropenia did not reduce the endotoxin-stimulated increase in the PAF concentrations in the lungs suggests that neutrophils were not necessary for lung PAF synthesis. Since Camussi and colleagues $(39,40)$ have recently reported both in vivo and in vitro release of PAF from injured pulmonary endothelial cells, and since pulmonary endothelial injury is a prominent finding in endotoxemia, the pulmonary endothelial cells appear to be likely sources of PAF in this study. Yet contributions from other lung parenchymal cells cannot be excluded. Our finding of increased PAF in the kidney 90 min after endotoxin suggests a similar process occurring in renal cells.

In view of the high levels of PAF in the lungs, the lack of an increase in lung lavage PAF concentrations after endotoxin was unexpected. We conclude that the lung lavage PAF concentration did not reflect lung tissue concentrations and further that this discrepancy was not due to a lack of carrier protein in the lavage fluid, but probably due to a lack of PAF producing cells in the 
alveolar space 90 min after endotoxin. Indeed, previous workers have suggested that in rats treated with endotoxin, an inflammatory alveolitis was not detectable until $24 \mathrm{~h}$ after endotoxin injection $(41,42)$. That the absence of PAF in the lung lavage fluid is not simply due to our inability to measure PAF in the lavage fluid is illustrated by our recovery of a large amount of PAF from the lungs treated with calcium ionophore A 23187. In addition, the recovery of PAF in the pulmonary lavage fluid has been reported by others $(43,44)$.

In our whole animal study, we focused on the early hemodynamic alterations following endotoxin injection and found that in awake, catheter-implanted rats, high-dose endotoxin (20 $\mathrm{mg} / \mathrm{kg}$ ) caused an acute drop in cardiac output associated with systemic and pulmonary hypotension and markedly impaired hypoxic pressor responses. On the other hand, a lower dose of endotoxin $(2 \mathrm{mg} / \mathrm{kg})$ caused similar impairment in hypoxic pressor responses without significantly affecting the cardiac output or systemic and pulmonary artery pressures. The resultant calculated systemic and total pulmonary vascular resistances increased in the first hour after high-dose endotoxin injection. Similar to previous studies $(1,7)$, endotoxin caused acute hyperventilation, metabolic acidosis, and leukopenia. In this study we found that CV 3988 protected against the endotoxin-induced systemic hypotension. This protective effect of CV 3988, which is similar in magnitude to that reported by Terashita et al. (9), is likely due to PAF receptor antagonism because (a) CV 3988 is a specific blocker of PAF effects in both in vitro and in vivo studies $(26,45)$. With the dose used in our study, CV 3988 failed to inhibit the hypotensive action of acetylcholine, arachidonic acid, bradykinin, isoproterenol, and histamine (26). (b) CV 3988 abolished the PAF induced pulmonary and systemic vasodilation in awake rats as well as the PAF-induced relaxation of precontracted pulmonary artery rings (46). (c) Structurally dissimilar PAF receptor antagonists, kadsurenone (10) and BN 52021 (47), likewise inhibited endotoxin-induced systemic hypotension.

In addition, we demonstrated that both CV 3988 and SRI 63-441 improved the impaired hypoxic pressor response after endotoxin. Because PAF was found in high concentrations in the lung after endotoxemia and because PAF may cause pulmonary vasodilation in rats during hypoxia $(46,48)$, PAF may mediate, at least in part, the decrease in hypoxic pressor response after endotoxin treatment. That we failed to show pulmonary vasodilation despite the presence of a large amount of PAF in our endotoxin model may be attributable to the presence of other mediators that act as pulmonary vasoconstrictors (2-5). Nevertheless, our data in awake rats with the two structurally independent PAF receptor antagonists suggest that PAF may act in the pulmonary circulation by blunting the hypoxic pressor reactivity in endotoxin-treated rats. Previous experiments demonstrated that inhibition of cyclooxygenase preserved hypoxic vasoconstriction in anesthetized dogs $(49,50)$ but not in unanesthetized sheep (51), suggesting that vasodilator prostaglandins can not fully explain the endotoxin-induced alteration in pulmonary vasoreactivity. Although our observations do not resolve the discrepancy between the earlier dog and the more recent sheep studies, one might speculate that PAF could act in part via stimulation of vasodilator prostaglandin production (13), which might be species-specific (52).

In this study, we used the extravascular leakage of ${ }^{125} \mathrm{I}$-albumin as an index of pulmonary vascular permeability in perfused lungs and documented a consistent increase in this index in the lungs isolated from endotoxin-treated rats. Other than changes in pulmonary vascular permeability, the major factors that can theoretically influence the ${ }^{125} \mathrm{I}$-albumin leak index include the transvascular pressure in the microvessels and the perfused area of the lung (53). It is unlikely that differences in transvascular pressure account for our finding inasmuch as the microvascular pressure estimated by the double-occlusion method did not differ in the lungs from endotoxin-treated and control animals. Furthermore, we have attempted to remove major differences in the perfused vascular area by using rats of comparable body size and by adding papaverine to the perfusate to block active vasoconstriction. Overall, we feel that changes in the ${ }^{125} \mathrm{I}$ albumin leak index reflect changes in pulmonary vascular permeability, and that our data are consistent with acute lung vascular injury in the endotoxin-treated rats.

An important result of this study is that two PAF receptor antagonists, CV 3988 and SRI 63-441, inhibited the endotoxininduced lung vascular leak. Although less information is available on the action of SRI 63-441 than on CV $3988(26,45)$, one published report suggests that SRI $63-441$ is a potent antagonist of PAF action in the rat (27). Other reports indicated that the increased vascular permeability due to PAF could be blocked by CV 3988 (54) and SRI 63-441 (27). In addition, recent studies from our laboratory demonstrated that CV 3988 blocked the increase in water content of isolated perfused rat lungs after bolus injection of PAF (46). Taken together, these studies suggest that PAF may be an important mediator in the development of endotoxin-induced lung injury. It is unclear why RP 48740, which has been shown to block PAF effects in guinea pigs (31), was ineffective against the endotoxin-induced lung vascular leak in our study. It is possible that the dose used was inadequate because, in our previous study (46), RP 48740 was less potent than CV 3988 against PAF effects in both rabbit platelets and isolated rat lungs. Alternatively, the ineffectiveness of RP 48740 could reflect the variable abilities of different PAF antagonists to bind to different PAF receptor subtypes (55).

How PAF promotes lung injury after endotoxemia is unknown and our results in whole animals cannot distinguish between direct and indirect actions of PAF. Indeed, whether PAF directly interacts with the vascular endothelium to cause increased vascular permeability remains controversial (14-16, 56, 57). We have recently shown that in lungs perfused with bloodfree solution, the edemagenic effect of PAF is dependent on pulmonary vasoconstriction (58). However, our present data do suggest the importance of an interaction between PAF and neutrophils for endotoxin-induced lung injury because neutropenia (which did not block the increase in lung PAF level after endotoxin) also protected the rats against the increased lung vascular permeability after endotoxin. The finding that neutropenia inhibited endotoxin-induced lung injury has been previously reported in sheep (59). One may speculate that PAF stimulates the neutrophils that are sequestered in the lung circulation to release increased amounts of toxic oxygen metabolites, lysosomal contents, and other mediators and thus causing lung injury (60). Whether PAF alone, in the absence of neutrophils, would cause more subtle lung damage not measured by the methods described in this study is not known.

Although CV 3988 and SRI 63-441 blocked the endotoxininduced hemodynamic and pulmonary vascular permeability changes, they did not protect against the leukopenia, and only SRI 63-441 affected the metabolic acidosis in the endotoxin- 
treated rats. In addition, in this and other studies $(9,10)$ the protection against the endotoxin-induced hypotension by the PAF antagonists was incomplete. Thus, other mechanisms including the actions of other inflammatory mediators such as thromboxane, prostaglandins, leukotrienes, and tumor necrosis factor, as well as the synergistic effect of several mediators need to be considered $(2-8,61)$. Recently, Chilton et al. (62) have proposed that PAF and arachidonic acid are derived from a common precursor molecule (1-O-alkyl-2-arachidonoyl-snglycero-3-phosphocholine), and that arachidonic acid and lysoPAF may be generated by a common stimulus. The demonstration that lung PAF, along with other arachidonic acid products (2-4), increased after endotoxemia is consistent with this hypothesis. In addition, interactions between these inflammatory mediators are possible. We have shown previously (63) that injection of PAF into isolated rat lungs led to production of leukotrienes. Others have reported that PAF stimulated the release of cyclooxygenase products in vivo $(13,64)$. The interaction between tumor necrosis factor, a recently described protein mediator of endotoxic shock (61), and these lipid mediators are presently unclear. In the complex events after endotoxemia, it is likely that blockade of one of the more proximal mediators could interrupt the inflammatory cascade, thus leading to a measurable improvement. However, to provide complete protection, one may need to block several steps in this cascade.

\section{Acknowledgments}

We thank Ken Morris for technical assistance with the rat catheterizations and John Seccombe for performing the PAF bioassay. In addition, Gary Zerbe in the Department of Biostatistics, Keith Clay in the Department of Pharmacology, and Tina Leslie in the Department of Pathology provided many kind and helpful suggestions. We are grateful to Eva Toyos and Steve Hofmeister for providing the artwork and Michele Jones for typing the manuscript.

This work was supported by the National Institutes of Health (Program Project Grant HL-14985) and the American Lung Association (Career Development Award to Dr. Voelkel). C. O. Feddersen was a recipient of a grant from the Deutsche Forschungsgemeinschaft, Bonn Bad Godesberg.

\section{References}

1. Brigham, K. L., C. J. Begley, G. R. Bernard, A. A. Hutchison, J. E. Loyd, W. D. Lucht, B. Meyrick, J. H. Newman, M. E. Niedermeyer, M. L. Ogletree, J. R. Sheller, and J. R. Snapper. 1983. Septicemia and lung injury. Clin. Lab. Med. 3:719-744.

2. Cook, J. A., W. C. Wise, and P. V. Halushka. 1980. Elevated thromboxane levels in the rat during endotoxic shock. J. Clin. Invest. 65:227-230.

3. Demling, R. H., M. Smith, R. Gunther, J. T. Flynn, and M. H. Gee. 1981. Pulmonary injury and prostaglandin production during endotoxemia in conscious sheep. Am. J. Physiol. 240:H348-H353.

4. Hagmann, W., C. Denzlinger, and D. Keppler. 1985. Production of peptide leukotrienes in endotoxin shock. FEBS (Fed. Eur. Biochem. Soc.) Lett. 180:309-313.

5. Winn, R., J. Harlan, B. Nadir, L. Harker, and J. Hildebrand. 1983. Thromboxane $A_{2}$ mediates lung vasoconstriction but not permeability after endotoxin. J. Clin. Invest. 72:911-918.

6. Begley, C. J., M. L. Ogletree, B. O. Meyrick, and K. L. Brigham. 1984. Modification of pulmonary responses to endotoxemia in awake sheep by steroidal and nonsteroidal anti-inflammatory agents. Am. Rev. Respir. Dis. 130:1140-1146.
7. Cook, J. A., W. C. Wise, and P. V. Halushka. 1985. Protective effect of a selective leukotriene antagonist in endotoxemia in the rat. $J$. Pharmacol. Exp. Ther. 235:470-474.

8. Henson, P. M., G. L. Larson, R. O. Webster, B. C. Mitchell, A. J. Goins, and J. E. Henson. 1982. Pulmonary microvascular alterations and injury induced by complement fragments: synergistic effects of complement activation, neutrophil sequestration, and prostaglandins. Ann. N.Y. Acad. Sci.384:287-300.

9. Terashita, Z., Y. Imura, K. Nishikawa, and S. Sumida. 1985. Is platelet activating factor a mediator of endotoxic shock? Eur. J. Pharmacol. 109:257-261.

10. Doebber, T. W., M. S. Wu, J. C. Robbins, B. M. Choy, M. N. Chang, and T. Y. Shen. 1985. Platelet activating factor involvement in endotoxin-induced hypotension in rats: studies with PAF-receptor antagonist kadsurenone. Biochem. Biophys. Res. Commun. 127:799-808.

11. Inarrea, P., J. Gomez-Cambronero, J. Pascual, M. del Carmen Ponte, L. Hernando, and M. Sanchez-Crespo. 1985. Synthesis of PAFacether and blood volume changes in gram-negative sepsis. Immunopharmacology. 9:45-52.

12. Caillard, G., S. Mondot, J. L. Zundel, and L. Julou. 1982. Hypotensive activity of PAF-acether in rats. Agents Actions. 12:725-730.

13. Bessin, P., J. Bonnet, D. Apffel, C. Soulard, I. Desgroux, I. Pelas, and J. Benveniste. 1983. Acute circulatory collapse caused by plateletactivating factor in dogs. Eur. J. Pharmacol. 86:403-413.

14. Mojarad, M., Y. Hamasaki, and S. I. Said. 1983. Platelet-activating factor increases pulmonary microvascular permeability and induces pulmonary edema. Bull. Eur. Physiopathol. Respir. 19:253-256.

15. Handley, D. A., C. M. Arbeeny, M. L. Lee, R. G. Van Valen, and R. N. Saunders. 1984. Effect of platelet activating factor on endothelial permeability to plasma macromolecules. Immunopharmacology. 8:137-142.

16. Cox, C. P., M. Mojarad, A. Attiah, and S. I. Said. 1984. Plateletactivating factor increases pulmonary vascular permeability in awake sheep. Am. Rev. Respir. Dis. 129:A334. (Abstr.)

17. Grandel, K. E., R. S. Farr, A. A. Wanderer, T. C. Eisenstadt, and S. J. Wasserman. 1985. Association of platelet-activating factor with primary acquired cold urticaria. N. Engl. J. Med. 313:405-409.

18. Hunnighake, G. W., J. E. Gadek, O. Kawanami, V. J. Ferrano, and R. G. Crystal. 1979. Inflammatory and immune processes in the human lung in health and disease: evaluation by bronchoalveolar lavage. Am. J. Pathol. 97:149-206.

19. Benveniste, J. 1974. Platelet-activating factor, a new mediator of anaphylaxis and immune complex deposition from rabbit and human basophils. Nature (Lond.). 249:581-582.

20. Lemanske, R. F., Jr., D. A. Guthman, H. Oertel, L. Barr, and M. Kaliner. 1983. The biologic activity of mast cell granules. VI. The effect of vinblastine-induced neutropenia on rat cutaneous late phase reactions. J. Immunol. 130:2837-2842.

21. Bligh, E. G., and W. J. Dyer. 1959. A rapid method of total lipid extraction and purification. Can. J. Biochem. Physiol. 37:911-917.

22. Henson, P. M. 1976. Activation and desensitization of platelets by platelet-activating factor derived from IgE-sensitized basophils. I Characteristics of the secretory response. J. Exp. Med. 143:937-952.

23. Coleman, T. G. 1974. Cardiac output by dye dilution in the conscious rat. J. Appl. Physiol. 40:266-268.

24. Stanbrook, H. S., K. G. Morris, and I. F. McMurtry. 1984. Prevention and reversal of hypoxic pulmonary hypertension by calcium antagonists. Am. Rev. Respir. Dis. 130:81-85.

25. Huber, F., I. E. Sodal, and J. V. Weil. 1976. On-line cardiac output by digital computer. J. Appl. Physiol. 40:266-268.

26. Terashita, Z., S. Tsushima, T. Yoshioka, B. Nomura, Y. Inada, and K. Nishikawa. 1983. CV-3988, a specific antagonist of platelet activating factor. Life Sci. 32:1975-1982.

27. Handley, D. A., J. C. Tomesch, and R. N. Saunders. 1986. Inhibition of PAF-induced systemic responses in the rat, guinea pig, dog and primate by the receptor antagonist SRI 63-441. Thromb. Haemostasis. 56:40-44. 
28. McMurtry, I. F., A. B. Davidson, J. T. Reeves, and R. F. Grover. 1976. Inhibition of hypoxic pulmonary vasoconstriction by calcium antagonists in isolated rat lungs. Circ. Res. 38:99-104.

29. Johnson, K. J., and P. A. Ward. 1974. Acute immunologic pulmonary alveolitis. J. Clin. Invest. 54:349-357.

30. Dawson, C. A., J. H. Linehan, and D. A. Rickaby. 1982. Pulmonary microcirculatory hemodynamics. Ann. N.Y. Acad. Sci. 384:90106.

31. Coeffier, E., M. Borrel, L. Lefort, M. Chignard, C. Broquet, F. Hemans, and B. B. Vargaffig. 1985. Effect of PAF-acether antagonist, RP 48740 and BN 52021, on platelet activation and bronchoconstriction induced PAF-acether and structural analogues in guinea-pig. Prostaglandins. 30:699. (Abstr.)

32. Steel, R. G. D., and J. H. Torrie. 1960. Principles and Procedures of Statistics. McGraw-Hill Book Co., Inc., New York.

33. Scheffe, H. 1953. A method for judging all contrasts in the analysis of variance. Biometrika. 40:87-104.

34. Zerbe, G. O. 1979. Randomization analysis of growth and dose response curves. J. Am. Statist. Assoc. 74:215-221.

35. Petrondas, D. A., and R. K. Gabriel. 1983. Multiple comparisons by rerandomization tests. J. Am. Statist. Assoc. 78:949-957.

36. Pirotzky, E., J. Bidault, C. Burtin, M. C. Gubler, and J. Benveniste. 1984. Release of platelet-activating factor, slow-reacting substance, and vasoactive amines from isolated rat kidneys. Kidney Int. 25:404-410.

37. Meyrick, B., and K. L. Brigham. 1983. Acute effects of Escherichia coli endotoxin on the pulmonary microcirculation of anesthetized sheep: structure, function relationship. Lab. Invest. 48:458-470.

38. Rosenbaum, J. T., I. F. Charo, and I. M. Goldstein. 1983. Human polymorphonuclear leukocytes produce platelet-activating factor-like activity in response to endotoxin-activated serum. Clin. Res. 31:374A. (Abstr.)

39. Camussi, G., I. Pawlowski, F. Bussolino, P. R. B. Caldwell, J. Brentjens, and G. Andres. 1983. Release of platelet activating factor in rabbits with antibody-mediated injury of the lung: the role of leukocytes and of pulmonary endothelial cells. J. Immunol. 131:1802-1807.

40. Camussi, G., M. Aglietta, F. Malavasi, C. Tetta, W. Piacibello, F. Sanavio, and F. Bussolino. 1983. The release of platelet-activating factor from human endothelial cells in culture. J. Immunol. 131:23972403.

41. Rinaldo, J. E., J. H. Dauber, J. Christman, and R. M. Rogers. 1984. Neutrophil alveolitis following endotoxemia: enhancement by previous exposure to hyperoxia. Am. Rev. Respir. Dis. 130:1065-1071.

42. Chang, J. C., and M. Lesser. 1984. Quantitation of leukocytes in bronchoalveolar lavage samples from rats after intravascular injection of endotoxin. Am. Rev. Respir. Dis. 129:72-75.

43. Prevost, M-C., C. Cariven, M. F. Simon, H. Chap, and L. DousteBlazy. 1984. Platelet activating factor (PAF-acether) is released into rat pulmonary alveolar fluid as a consequence of hypoxia. Biochem. Biophys. Res. Commun. 119:58-63.

44. Fasules, J., K. R. Stenmark, P. M. Henson, N. F. Voelkel, A. Tucker, and J. T. Reeves. 1986. Platelet activating factor in lung lavage of chronically hypoxic neonatal calves. Am. Rev. Respir. Dis. 133:A227. (Abstr.)

45. Terashita, Z., Y. Imura, and K. Nishikawa. 1985. Inhibition by CV 3988 of the binding of $\mathrm{H}_{3}$-platelet activating factor to the platelet. Biochem. Pharmacol. 34:1491-1495.

46. Voelkel, N. F., S. Chang, K. D. Pfeffer, S. G. Worthen, I. F. McMurtry, and P. M. Henson. 1986. PAF antagonists: different effects on platelets, neutrophils, guinea pig ileum and isolated rat lung. Prostaglandins. 32:354-372.

47. Adnot, S., J. Lefort, V. Lagente, P. Braquet, and B. B. Vargaftig. 1986. Interference of BN 52021, a PAF-acether antagonist, with endo- toxin-induced hypotension in the guinea pig. Pharm. Res. Commun. 18: 197-200.

48. McMurtry, I. F., and K. G. Morris. 1986. Platelet activating factor causes pulmonary vasodilation in the rat. Am. Rev. Respir. Dis. 134:757-762.

49. Weir, E. K., J. Mlczoch, J. T. Reeves, and R. F. Grover. 1976. Endotoxin and prevention of hypoxic pulmonary vasoconstriction. $J$. Lab. Clin. Med. 88:975-983.

50. Hales, C., L. Sonne, M. Peterson, D. Kong, M. Miller, and W. D. Watkins. 1981. Role of thromboxane and prostacyclin in pulmonary vasomotor changes after endotoxin in dogs. J. Clin. Invest. 68: 497-505.

51. Hutchison, A. A., M. L. Ogletree, J. R. Snapper, and K. L. Brigham. 1985. Effect of endotoxemia on hypoxic pulmonary vasoconstriction in unanesthetized sheep. J. Appl. Physiol. 58:1463-1468.

52. Voelkel, N. F. 1985. Species variation in lung arachidonic acid metabolism. Prostaglandins. 29:867-889.

53. Drake, R., K. A. Gaar, and A. E. Taylor. 1978. Estimation of the filtration coefficient of pulmonary exchange vessels. Am. J. Physiol. 234:H266-H274.

54. Melden, M. K., R. G. VanValen, M. L. Lee, R. N. Saunders, and D. A. Handley. 1985. Inhibition of PAF-induced bronchoconstriction and hemoconcentration in the guinea pig by CV 3988. Fed. Proc. 44: 1268. (Abstr.)

55. Lambrecht, G., and M. J. Parnham. 1986. Kadsurenone distinguishes between different platelet activating factor receptor subtypes on macrophages and polymorphonuclear leukocytes. Br. J. Pharmacol. 87: 287-289.

56. Heffner, J. E., S. A. Shoemaker, E. M. Canham, M. Patel, I. F. McMurtry, H. G. Morris, and J. E. Repine. 1983. Acetylglyceryl ether phosphorylcholine-stimulated human platelets causing pulmonary hypertension and edema in isolated rabbit lungs. J. Clin. Invest. 71:351357.

57. Bolin, R. W., R. K. Albert, and T. M. Martin. 1986. Platelet activating factor does not increase vascular permeability in isolated rabbit lung. Am. Rev. Respir. Dis. 133:A279. (Abstr.)

58. Voelkel, N. F., S. Chang, A. Sakai, and A. Harris. 1986. The importance of pulmonary vasoconstriction in the $\mathrm{LTC}_{4}$ and PAF-induced lung edema. In Proceedings of the Sixth International Conference on Prostaglandins and Related Compounds. Florence, Italy, June 3-6, 1986. Raven Press, New York. 79. (Abstr.)

59. Heflin, A. C., Jr., and K. L. Brigham. 1981. Prevention by granulocyte depletion of increased vascular permeability of sheep lung following endotoxemia. J. Clin. Invest. 68:1253-1260.

60. Shaw, J. O., R. M. Pinckard, K. S. Ferrigni, L. M. McManus, and D. J. Hanahan. 1981. Activation of human neutrophils with 1-Ohexadecyl/octadecyl-2-acetyl-sn-glyceryl-3-phosphorylcholine. J. Immunol. 127:1250-1255.

61. Tracey, K. J., B. Beutler, S. F. Lowry, J. Merryweather, S. Wolpe, I. W. Milsarb, R. J. Hariri, T. J. Fahey III, A. Zenteila, J. D. Albert, G. T. Shires, and A. Grami. 1986. Shock and tissue injury induced by recombinant human cachectin. Science (Wash. DC). 234:470-474.

62. Chilton, F. H., J. M. Ellis, S. C. Olson, and R. L. Wykle. 1984. 1-O-alkyl-2-arachidonoyl-sn-glycero-3-phosphocholine: a common source of platelet activating factor and arachidonate in human polymorphonuclear leukocytes. J. Biol. Chem. 259:12014-12019.

63. Voelkel, N. F., S. Worthen, J. T. Reeves, P. M. Henson, and R. C. Murphy. 1982. Nonimmunological production of leukotrienes induced by platelet-activating factor. Science (Wash. DC). 218:286-288.

64. Lefer, A. M., H. F. Muller, and J. B. Smith. 1984. Pathophysiological mechanisms of sudden death induced by platelet activating factor. Br. J. Pharmacol. 83:125-130. 